\title{
EDITORIAL
}

\section{¡A propósito de Navidad!}

\author{
Pío Gómez Moreno. M.D (q.e.p.d); Pío Iván Gómez Sánchez
}

La palabra Navidad está íntimamente ligada a la época de nuestra infancia y nos retrotrae a esas escenas vividas y vividas en aquellos idílicos días ya lejanos. Su tradición familiar nos viene desde nuestros abuelos y nuestros padres y la hemos repetido en la adolescencia y juventud con la misma inefable emoción con que la escuchábamos de niños.

\section{Origen semántico o etimológico del vocablo Navidad}

Esta palabra es una contracción de Natividad, originaria de la lengua latina: nativitas-nativitatis, que significa nacimiento, especialmente el de Jesucristo.

Trae consigo la Navidad diversas asociaciones de cordialidad manifestadas a la lumbre hogareña $o$ añoranzas, evocando en ellas los seres desaparecidos, constituyéndose en un lacrimario.

Veamos cuáles fueron las fuentes primigenias de las celebraciones navideñas y de los diversos símbolos que entraña, llevando consigo la dulzura a los niños, la alegría a los jóvenes y tornando felices o lúgubres las remembranzas para quienes ya, en el crepúsculo gris de su vida, ven iluminadas sus canas por la nunciadora estrella Belentina.

Los antiguos romanos celebraban estas fiestas paganas durante el solsticio de invierno. El término solsticio se deriva del latín: sol-solis, sol-statio-stationis, postura, aparente quietud. El solsticio es la época en que el sol se halla en uno de los trópicos, Cáncer o Capricornio: existen dos solsticios: el de verano, que se efectúa entre el 21 y el 22 de Junio y el de invierno o hiemálico (hiemas-hiemalis-invierno), que se verifica del 21 al 22 de diciembre.

Cuentan las crónicas de la antigüedad que los hechos navideños se originaron en los ritos que los Celtas, oriundos de Asia y extendidos por toda Europa, celebraban antes de Cristo y durante el solsticio hiemálico o de invierno; posteriormente, en el siglo IV, los cristianos festejaban la Navidad y pascuas incluyendo en ellas un leño ardiendo: el nochebueno; en repostería también se llama nochebueno a la torta de almendras y piñones que se sirve en Navidad mientras las familias se sientan a manteles.

\section{Origen del pesebre}

En relación con el origen del pesebre (palabra tomada del latín praesepium: establo), en el cual, según costumbres

Profesor Asociado. Universidad Nacional de Colombia. tradicionales, se colocan figurillas arcillosas o talladas en madera y que representan al niño Jesús, la Virgen y San José, junto a ellas hay un mulo y un buey, un ángel alado portando una cinta que reza: "Gloria in excelsis Deo", cuyo conjunto se denomina Nacimiento. Esto se atribuye a San Francisco de Asís, quien en el año 1223, cuando al llegar a un convento dijo: "Deseo celebrar aquí la nochebuena; que coloquen en el monte más cercano un pesebre, un asno y un buey, como se hizo en Belén, pues deseo recordar con toda solemnidad la venida del hijo de Dios".

Hoy nosotros con dulce nostalgia (del griego nostos, retorno; algos, dolor; pesar que causa el recuerdo de lo perdido), rememoramos aquellas veladas presepianas de inolvidables años ya muy distantes.

\section{Origen de Papá Noel}

Acerca de aquel personaje atrayente, quien presidido de un halo de sencillez y simpatía cautivantes, de luengas y nevadas barbas, ojos de un claro azul celeste y en cuyas espaldas carga un saco de regalos, es la personificación de San Nicolás de Bari, nacido en Asia menor, obispo de Mira en el siglo IV y patrono de Rusia. Se celebra su fiesta el 6 de diciembre, acontecimiento muy parecido al de los Magos. San Nicolás, después de haber regresado de un viaje de Egipto y Palestina, fue elegido obispo de Mira, y encarcelado por Diocleciano (245-313) y posteriormente liberado por Constantino (284-305). La leyenda lo convirtió en el proveedor de juguetes a los niños en vísperas de Navidad; en los países germanos se le conoce con el nombre de Santa Claus, contracción de SanetaNicolaus. Su bizarría es legendaria y en verdad se cuenta: "Un aristócrata arruinado no podía dotar a sus hijas y estaba a punto de abandonarlas a una vida de pecado; enterado el joven Nicolás, quien había heredado una cuantiosa fortuna dejó secretamente un pañuelo colmado de monedas de oro en una ventana de la casa, con este caudal y otros donativos sucesivos, consiguió el aristócrata en mención casar a sus hijas; se cuenta que en uno de los regalos cayó una media que pendía de la chimenea, lo cual dio origen de colgar una media en la noche de Navidad".

En Francia se dice Bonhome Noel a un personaje celeste parecido a Santa Claus y que, según creencias infantiles, se encarga de distribuir juguetes y golosinas a los niños que han sido buenos, deposita los regalos en la chimenea a condición que pongan en ella los zapatos, cuando los niños no han sido buenos, les trae en vez de dádivas un haz de ramas. 


\section{Origen del árbol de navidad}

Este parece haber tenido su nacimiento en Roma y de ahí se generalizó a los pueblos germanos. Se cuenta que el príncipe Alberto lo generalizó en Europa. Se atribuye a Martín Lutero el primer árbol de navidad iluminado al intentar explicar a su hijo cómo relucían las estrellas en el bosque a través de los pinos, al volver a su casa por la noche.

\section{Cómo se originaron los aguinaldos}

Los dátiles y miel eran especies de estrenas o dádivas (en latín, strena, strenae), presente, donación, regalo. Estas primitivas oferencias eran usadas por los antiguos príncipes y patrones como regalos a sus vasallos, especialmente al principio del año. Desde ésa época se conoció la costumbre de dar dátiles y miel para indicar a quienes recibían dichos presentes el deseo que en el resto del año no les ocurriese más que cosas placenteras; más tarde, cuando los romanos perdieron la austeridad en el vivir, enviábanse monedas y medallas de plata, llegando a hacerse esta costumbre tan general, que todo el pueblo llevaba el primero del año al emperador, al tiempo de felicitarle y desearle un nuevo año muy próspero. Estas ofrendas, estrenas o regalos dieron origen a los aguinaldos.

En la edad media, los aguinaldos se generalizaron en todas las clases sociales, lo mismo entre los poderosos que entre los humildes, viniendo a resultar como sucede ahora, un verdadero cambio de regalos. Hoy el dar y recibir aguinaldos es una costumbre cosmopolita.

\section{Leyenda de los Magos como Reyes}

Venían estos del Oriente, más allá del Jordán, a través del desierto Sirioarábigo (Mesopotamia), o sea la ciudad entre dos ríos, el Eufrates y el Tigris; los Magos eran individuos de la clase sacerdotal en la religión Zoroástrica o Mazdeismo (del persa Mazda, sobrenombre del rey del cielo y príncipe del bien). Religión de los antiguos persas que creían en la existencia de dos principios divinos: uno bueno, Ormuz, creador del mundo y otro malo, Ahrimán, destructor. Se les dice comúnmente los Reyes Magos y pertenecían a una clase sacerdotal en Persia y Babilonia así como en gran parte de Oriente; más las pinturas antiguas los representaban sin insignias reales y así mismo San Mateo o Levi, en su evangelio, al mencionarlos, tampoco afirma su realeza, al decir de él: "nacido, pues, Jesús de Belén de Judá en los días del Rey Herodes, llegaron del Oriente a Jerusalén y diciendo: dónde está el Rey de los Judíos que acaba de nacer, porque hemos visto su estrella en el Oriente y venimos a adorarle". Estos personajes eran oriundos de Media, donde constituían una clase sacerdotal y se distinguían por su afición al estudio de la Astronomía, mejor Astrología, que era una ciencia adivinatoria basada en los principios de que la vida de los hombres se desarrolla bajo la influencia de los astros. Esta ciencia de la Astrología ha sido continuada hoy bajo el nombre de Cosmobiología, o estudio de la influencia planetaria en el desarrollo y evolución del conjunto biológico de la creación, especialmente del hombre.

\section{El origen de los Villancicos}

Se denomina Villancico "una composición poética popular con estribillo y en especial la de asuntos religiosos; se canta en las iglesias, generalmente en Navidad. También se dice que es canción a lo villano, a lo popular pero a lo campestre y rústico". Canción o tonada ingenua, cuya poesía y música inventa la gente campesina y que tomada luego por el artista, después de haberse asimilado su espíritu, es revestida de formas diversas, constituyendo esa clase de composición que fluctúa entre la expresión plebeya y la culta y después ha sido clasificada en la literatura castellana con diversos títulos entre ellos el de madrigal, vale decir: "Composición poética en que se expresa con ligereza y galanura un afecto o pensamiento delicado". El villancico apareció a principios del siglo XVI como manifestación del sentimiento religioso popular, formando parte de las festividades de Navidad. La forma general del villancico Sacro es la siguiente: "Comienza y termina por una parte coral que se llama estribillo y la central constituida por varios pasajes para una sola voz llamados coplas. Anglosajónicamente se denomina el Villancico CHRISTMAS CHORAL, vale decir, Villancico Navideño".

\section{Epílogo}

Reseñadas así, con íntima melancolía, aquellas escenas transcurridas en nuestra infancia y aún en la adolescencia ya lejanas, quisiéramos retrotraer el cuadrante del tiempo para aún renovarlas, sentirlas y soñarlas, reclinándonos ante esas preterizaciones que ahora se presencian en nuestros días a través del tiempo y la distancia, de épocas ya fenecidas.

¿Qué anacronismo en el que se mueven y realizan hoy estas fiestas de pascuas y navidad!, quisiéramos que estos tiempos fueran sincrónicos con nuestro pasado, para no lanzar las imprecaciones a que nos vemos abocados en los días que nos circundan.

La iconoclasia reinante, por el mercantilismo absorbente y grosero, la sustitución de aquellos tradicionales símbolos navideños, por la entronización de usos y abusos esnóbicos, desperfilan y, por ende, menguan el encanto y espiritualidad de las navidades de antaño, tan reñidas como las de hogaño, en las cuales imperan el menosprecio y abandono por aquellos valores intrínse$\cos$, que fueron canteras inagotables de un dorado $y$ perenne romanticismo que añoramos. 